\title{
TEORIA DA RESTAURAÇÃO: CESARE BRANDI - NORTEANDO AS INTERVENÇÕES SEM FALSO HISTÓRICO E FALSO ARTÍSTICO
}

Ana Clara Ribeiro de Andrade Santos, lesmin Yamada Ubida, Fabrícia Dias da Cunha de Moraes Fernandes Borges

Universidade do Oeste Paulista - UNOESTE, Curso de Arquitetura e Urbanismo, Presidente Prudente, SP.

\section{RESUMO}

O presente artigo tem como finalidade apresentar um estudo sobre a Teoria da Restauração proposta por Cesare Brandi, apresentando sua forma de pensamento nas intervenções em obras históricas, dentre elas, a arquitetônica. Com seus axiomas e lacunas, Brandi norteianos para a concepção de um restauro sem cometer um falso histórico e artístico, respeitando assim as passagens do tempo e sua estética original que a obra apresenta, além do preenchimento das lacunas para melhor entendimento da obra em si. Para tanto, foi realizado um estudo de sua teoria, baseado em pesquisas bibliográficas, afim de melhor compreensão da mesma. Com isso, pôde-se aplicar a teoria em uma obra, o Museu do Pão, levando em conta toda a análise teórica compreendida.

Palavras-chave: Cesare Brandi; Teoria da Restauração; Intervenções; Restauro Crítico; Museu do Pão.

\section{THEORY OF RESTORATION: CESARE BRANDI - NORTEANDO INTERVENTIONS WITHOUT HISTORICAL FALSE AND ARTISTIC FALSE}

\begin{abstract}
The present article aims to present a study on the Theory of Restoration proposed by Cesare Brandi, presenting his form of thought in the interventions in historical works, among them, the architectural one. With its axioms and gaps, Brandi guides us towards the conception of a restoration without committing a false historical and artistic, respecting thus the passages of time and its original aesthetic that the work presents, in addition to filling the gaps for a better understanding of the work in Yes. For that, a study of his theory, based on bibliographical research, was carried out in order to better understand it. With this, one could apply the theory in a work, the Museum of Bread, taking into account all the theoretical analysis understood.
\end{abstract}

Keywords: Cesare Brandi; Theory of Restoration; Interventions; Critical Restoration; Bread Museum. 


\section{INTRODUÇÃO}

Cesare Brandi nasceu em 8 de abril de 1906 em Siena, na Itália. É dono do conceito do Restauro Crítico, o qual analisa todas as obras consideradas obras de arte, que segundo Brandi (2008), são todas as coisas que tenham um testemunho da ação do homem, para que não haja intervenções inadequadas - como um falso histórico e artístico -, sem intervir para que volte no momento da criação e sim que continue carregando as marcas do tempo. Segundo Carmo et al. (2016), Brandi se formou em Direito e Ciências Humanas, e em 1930 estreou seus trabalhos como supervisor de monumentos e galerias, e na Administração das Antiguidades e Belas Artes em Siena, Itália, intervindo também na Universidade de Roma em 1934, sendo convocado posteriormente, pelo inspetor geral de Belas Artes e Professor de História da Arte Moderna, Giulio Carlo Argan (1909-1992), à organizar o Instituto Central de Restauro (ICR), e assim, em 1939, tornou-se diretor do mesmo até 1960.

Ainda nesse contexto, o autor afirma que Brandi estreou seu trabalho junto à Unesco como especialista em 1948, concebendo inúmeras obras relacionadas a sua experiência junto ao ICR, e ao sair do cargo de diretor do mesmo, Brandi se dedicou inteiramente às avaliações sobre a arte e monumentos que por conseguinte desenvolveu as primeiras linhas sobre esse tema, denominada Teoria do Restauro Crítico.

O autor em questão teve grandes trabalhos publicados, como Pellegrino di Puglia (1960), Disegno Dell'Architettura Italiana (1985), Teoria Generale Della Critica (1974) e Teoria Del Restauro (1963) sendo esse o principal livro realizado por ele, onde o mesmo aplica a sua experiência conquistada durante o período em que foi diretor do Istituto Centrale del Restauro de Roma (ICR), nele apresenta a sua capacidade intelectual e sua teoria - brandiana - em relação à preservação de bens culturais e restauração dos patrimônios, patenteando minunciosamente a aplicação dos seus conceitos em obras de arte e monumentos (KÜHL, 2007).

O objetivo deste artigo é descrever, analisar e conhecer um dos autores mais relevantes da Teoria da Conservação e do Restauro que contribuiu para a reflexão e a prática da restauração, Cesare Brandi. Para tanto faz-se necessário levantamentos bibliográficos para a compreensão de conceitos pertinentes afim de entender sua teoria e forma de pensar, além da aplicação prática em obras, tendo como obra escolhida para este estudo, o Museu do Pão.

\section{TEORIA BRANDIANA}

Entende-se por restauração a intervenção com função de reativar a eficiência de um produto feito pelo homem (BRANDI, 2008), sendo este o seu primeiro corolário, que só se restaura o que é obra de arte e só é vista como tal quando esta é reconhecida como uma. As obras de arte segundo Brandi (2008), são todos os objetos e produtos de testemunho da atuação humana em um certo tempo e lugar, incluindo a historicidade - testemunho histórico -, a estética - seu estilo artístico - e por ser uma obra de arte. Com isso, nota a estreita relação entre a obra de arte e a restauração. "Chega-se, desse modo, a reconhecer a ligação indissolúvel que existe entre a restauração e a obra de arte, pelo fato de a obra de arte condicionar a restauração e não o contrário" (BRANDI, 2008, p. 29).

A partir desse pensamento, surgem seus axiomas que norteiam o trabalho de conservação e restauro:

1‥ axioma: "restaura-se somente a matéria da obra de arte" (BRANDI, 2008, p. 3132), sem cometer falso artístico, sem intervir ou modificar o original da obra. 
2‥ axioma: "A restauração deve visar ao restabelecimento da unidade potencial da obra de arte, desde que isso seja possível sem cometer um falso artístico ou um falso histórico, e sem cancelar nenhum traço da passagem da obra de arte no tempo"(BRANDI, 2008 , p. 33). Brandi defende que o objeto restaurado não volte no momento da criação, e sim que continue carregando as marcas do tempo, respeitando a temporalidade e a sua conformação original.

A restauração, para representar uma operação legítima, não deverá presumir nem o tempo como reversível, nem a abolição da história. A ação de restauros, ademais, e pela mesma exigência que impõe o respeito da complexa historicidade que compete à obra de arte, não se deverá colocar como secreta e quase fora do tempo, mas deverá ser pontuada como evento histórico tal como o é, pelo fato de ser ato humano e de se inserir no processo de transmissão da obra de arte para o futuro. (BRANDI, 2008, p. 61)

Deve-se manter o máximo do original e ao criar uma obra como um todo, uma unidade composta por partes - que também são obras de arte -, formaria uma identidade com diversas percepções e interpretações. Outro elemento importante defendido e estudado por Brandi (2008) seriam as Lacunas que, segundo ele, são uma interrupção no tecido figurativo para o entendimento completo da obra, uma falha, e que deve-se buscar meios para preencher isso (BRANDI, 2008, p. 50), ou seja, estabelecer essa lacuna, não deixando tanto em evidência para obstruir a obra original e ao mesmo tempo evidente, para que todos compreendam que foi adicionado para fechar a lacuna e assim, um melhor entendimento da obra completa. Um exemplo são os afrescos da Capela Mazzatosta na Igreja S. Maria della Verità, em Viterbo, Itália (BRANDI, 2008).

Outro elemento de grande interesse para ele, seria as ruínas, que, para ele seria o elemento que deveria ser mais preservado e mantido por serem um testemunho da história humana que retratam o passado e sua forma inicial e que agora encontra-se - em alguns casos - irreconhecível, mas mantém o seu potencial histórico. Elas são além de tudo um testemunho mutilado que se conserva total legitimidade de uma obra e também de um evento humano (BRANDI, 2008).

Como enfatiza o autor, as ruínas nem sempre foram ruínas, mas devido a sua degradação e/ou descaracterização ocasionadas pelas intempéries do tempo e mal preservação, essas não podem ser recompostas, não se pode ressuscitar um monumento, por isso são configuradas como um caso limite, o qual só é possível a sua conservação e intervenções (CUNHA, [200-]). Essa última deve se distinguir da obra original, os materiais podem ser os mesmos ou diferentes, mas ainda assim devem acentuar um limite capaz de identificar o novo e o antigo - isso também vale para obras antigas que ainda não sofreram total degradação. No caso de restauro, os materiais devem ser harmônicos à obra inicial de modo a não gerar incompatibilidade.

Todas as intervenções restauradoras devem ser reversíveis, sem danificar o material original, permitindo novas restaurações futuras e melhores técnicas que venham a ser desenvolvidas. Ainda nesse contexto, as intervenções deverão ser mínimas, justas e necessárias à estética da obra, bem como aspecto primordial à preservação do monumento em questão, devendo evitar a sua deterioração ao máximo e manter o seu caráter histórico documentado, para que assim seja profícuo para as futuras gerações (KÜHL, 2006). 


\section{INSPIRAÇÕES E FILOSOFIA}

Brandi se baseou nas teorias de Alois Riegl (1958-1905), em que o teórico afirmava que a importância dos monumentos do passado ficava somente com sua contribuição histórica e o que ela significava para a sociedade e não a sua conservação - de caráter eterno.

[...] tudo aquilo que foi, e não é mais hoje em dia. No momento atual, nós acrescentamos ainda a esse termo a ideia de que aquilo que foi não poderá jamais se reproduzir, e que tudo aquilo que foi constitui um elo insubstituível e intransferível de uma cadeia de desenvolvimento (RIEGL, 2001 apud CUNHA, 2006, p. 02).

Cunha (2006) afirma ainda que os monumentos devem respeitar o seu período histórico e a escola artística dessa época, e somente assim, eram considerados monumentos e a relação entre o monumento e a contemporaneidade, Riegl alega que este deve atender as necessidades materiais do homem, e a parte artística - a alma.

Brandi toma os estudos de Riegl como base, mas converge nos temas de conservação, como esclarece em sua obra Teoria da Restauração (2008). Primeiramente, Brandi formulou sua teoria voltadas para obras de arte, mas que podem ser aplicadas em projetos arquitetônicos com perfeita harmonia. Segundo Brandi (2008), uma obra de arte, ou monumento, deveria ser verificado se realmente é considerada como arte, como algo importante e de grande influência, e quando fosse restaurada, levar em conta a sua importância, os seus preceitos e estilos, e não restaurar no sentido literal da palavra, sendo a Arte condicionante do Restauro (BRANDI, 2008).

Mas sua principal inspiração no ramo filosófico, foi Edmund Husserl (1859-1938) e Hegel (1771-1831), com o universo da fenomenologia.

A partir dessa consciência e de uma ação crítica, o restaurador precisa agir buscando resgatar a sua unidade potencial, sem que produza falsificações ou que elimine a característica das passagens do tempo na obra. Em uma relação direta com a fenomenologia de Husserl, percebe-se que este princípio do pensamento brandiano apresenta, uma clara referência ao conceito de busca pela essência do objeto em análise na inserção dentro do contexto ao qual pertence (CARMO et al., 2016, p. 04).

Segundo Carbonara (2006), sua teoria se adequa ao restauro crítico, que se manifesta como uma corrente, o qual teve grande contribuição na estruturação teórica dos princípios de conservação e restauração na primeira metade do século XX - subsequente ao pósguerra. O mesmo desenvolveu-se na Itália, particularmente, no contexto arquitetônico, tendo como expoentes, além de Brandi, Roberto Pane (1897-1987) e Renato Bonelli (19112004). Esse restauro estabelece uma releitura das concepções associadas ao restauro filológico de Camillo Boito (1836-1914) e Gustavo Giovannoni (1873-1947), definidas em algumas cartas patrimoniais da década de 1930. A Carta de Veneza por exemplo, é legatária do restauro crítico e da teoria brandiana (KÜHL, 2010).

No restauro filológico, dava-se grande relevância aos princípios documentais das obras e aos vestígios do seu percurso no decorrer dos anos, respeitando sempre suas fases. O mesmo não objetivava em nenhum momento voltar ao seu estado original, no caso de acrescentar novos elementos, esses precisariam ser discernidos, ou seja, se diferenciar da obra para não instigar o observador ao equívoco - confundir a intervenção com a obra (KÜHL, 2010). 
Ainda nessa vertente, Kühl (2010) destaca que ao mesmo tempo em que abrange desses mesmos conceitos filológicos, o restauro crítico segue a obra do ponto de vista formal, documental e material, analisando as instâncias estéticas e históricas, oferecidos pelo pensamento crítico e científico do momento e na perspectiva metodológica a qual se interage por meio da dialética.

De acordo com Bonelli (apud KÜHL, 2010), o restauro é visto como ato de cultura, capaz de lidar com bens únicos e não reproduzíveis, possuinte de conhecimento em díspares âmbitos do saber.

\section{ARQUITETURA E A REPERCUSSÃO DA TEORIA}

Diferente de Viollet-le-Duc (1814-1879) que sofreu a influência direta da arquitetura Gótica e se dedicava, principalmente, a essa filiação arquitetônica a qual acreditava que pelo fato da obra ser de caráter gótico, ela já nascia com um grande significado simbólico (OLIVEIRA, 2009), Cesare Brandi não defendia uma filiação específica, o mesmo abarcava todos os estilos arquitetônicos e afirma ainda que independente da sua arquitetura a mesma ganhava significado devido ao seu âmbito histórico (KÜHL, 2007), que segundo ele:

Com efeito, dado que também a arquitetura, se tal, é obra de arte, como obra de arte goza da dúplice e indivisível natureza de monumento histórico e de obra de arte, e o restauro arquitetônico recai também sob a instância histórica e a instância estética (BRANDI, 2008, p. 131).

Portanto, Brandi acreditava que a arquitetura também era obra de arte e como tal, esta também era digna da aplicação de sua teoria que deveriam seguir os mesmos princípios imposto por ele na restauração e conservação das pinturas e esculturas, mas precisariam "ter presentes em primeiríssimo lugar a estrutura formal da arquitetura, que difere daquela das obras de arte, entendidas na acepção empírica supracitada" (BRANDI, 2008, p. 131-132).

Brandi (2008) ainda ressalta que as práticas de restauro desses monumentos arquitetônicos deveriam seguir alguns corolários ${ }^{1}$ determinados por ele sobre 0 reconhecimento da inalienabilidade do monumento levando em consideração o sítio em que estava inserido e seu valor histórico.

Felizmente, a teoria não é somente uma coletânea de textos que formam um manual de restauração como defende Kühl (2007), remetendo-se de uma complexa concepção e formulação do restauro, que oferece uma gama de conceitos para guiar a atividade prática da restauração, no entanto, muitos consideram que a teoria de Brandi é excessivamente teórica e filosófica, sem a prática.

Kühl (2007) destaca ainda que no livro, Cesare Brandi denota o conceito de restauração, discernindo o restauro de obras de arte - de aspectos estéticos e históricos - do restauro de produtos industriais - voltada à recuperação funcional -, visando na conservação da autenticidade material da obra restabelecendo sua unidade potencial.

Hoje o restauro e a conservação não se concentram somente no que se compreendia como obra de arte, mas se direcionam inclusive às obras modestas, exclusas anteriormente, mas com os anos acabaram por reconhecer e apresentar conotação cultural (KÜHL, 2007). A aplicação da teoria brandiana, está cada vez mais crescente, "[...] não apenas para as obras de arte, mas para todos os bens culturais, lembrando-se que mesmo não sendo obras de arte, possuem uma configuração e estratificações no tempo, as quais devem ser analisadas e respeitadas" (KÜHL, 2007, p. 203).

\footnotetext{
${ }^{1}$ Ver Cesare Brandi. Teoria da Restauração (2008, p. 133-134).
} 


\section{OBRA E TEORIA}

Como já mencionado, é perceptível a aplicação da Teoria Brandiana em monumentos arquitetônicos nos dias de hoje, um exemplo disso é o Museu do Pão - antigo Moinho Colognese - localizado em llópolis (RS), o qual foi restaurado pelo escritório paulista Brasil Arquitetura entre 2005 e 2007, com ajuda de parcerias. O Moinho foi construído em 1930 por uma família italiana assim como os demais moinhos da região que com o passar dos anos vieram a sofrer deteriorações. Como enfatiza Sambiasi (2011), “[...] apesar da sua importância histórica, estes moinhos estavam fadados a desaparecer, pelo abandono e esquecimento típicos de nossos dias" e com isso o escritório tinha como intuito a criação de uma rota turística - um Caminho dos Moinhos.

Ao efetuar o restauro e a intervenção baseando-se nas doutrinas de Cesare Brandi, eles reativaram a eficiência de um produto executado pelo homem dando uma função a ele e ao manter o máximo do original - Moinho Colognese -, respeitando a cultura da tradição italiana, eles reverenciaram sua historicidade resgatando a sua unidade potencial, sem produzir falsificações e/ou cópias a qual apaguem os traços da ação do homem no tempo, conservando assim, a sua autenticidade.

A intervenção foi feita de modo que se possa identificar o novo e o antigo (PACHALSKI, 2012), a mesma não se sobressai à preexistência, mas sim, a destaca ainda mais e para isso, seguindo a teoria brandiana, a utilização de materiais atuais - vidro e concreto armado - permitiu um diálogo harmonioso entre as edificações, não gerando conflito entre elas, e a aplicação do restauro crítico permitiu ainda que não houvesse uma intervenção impertinente o que geraria um falso histórico e artístico.

\section{CONSIDERAÇÕES FINAIS}

A partir dessa consciência, Brandi nos mostra a importância do respeito para com o tempo e a estética de uma obra, destacando que o restaurador precisa resgatar a sua unidade potencial, sem que produza falsificações ou que elimine a característica das passagens do tempo na obra. Inicialmente, sua teoria foi feita para as obras de arte, mas Brandi compreendeu que, o que se entende por obra de arte, era tudo que o homem produz ou produziu, estendendo assim sua teoria.

Com dois axiomas e com a fenomenologia como base, além do entendimento desta para a sua real aplicação, pode-se assim, realizar intervenções sem que firam ou cometam um falso histórico, levando em conta sempre a história do monumento ou obra de arte, reconhecendo sua potencialidade e protegendo sua identidade.

Portanto, pôde-se perceber o quanto a Teoria da Restauração de Brandi é tão reconhecida e seguida, pois, seus preceitos respeitam o caráter da identidade de uma obra, com suas lacunas e axiomas, guia-nos a um restauro limpo, para que todos tenham consciência e a lembrança de uma obra e sua história.

\section{REFERÊNCIAS}

BRANDI, C. Teoria da Restauração. Tradução de Beatriz Mugayar Kühl. Cotia - Ateliê Editorial, Coleção Artes \& Ofícios, 2008.

CARBONARA, G. Brandi e a restauração arquitetônica hoje. Desígnio, São Paulo, n. 6, p. 3547, 2006.

CARMO, F. H.; VICHNEWSKI, H.; PASSADOR, J.; TERRA, L. Cesare Brandi. Uma releitura da teoria do restauro crítico sob a ótica da fenomenologia. Arquitextos, São Paulo, ano 16, n. 
189.01, Vitruvius, fev. 2016. Disponível em: <http://www.vitruvius.com.br/revistas/read/arquitextos/16.189/5946>. Acesso em: 07 out. 2017.

CUNHA, C. R. Alois Riegl e o culto moderno dos monumentos. Resenhas Online, São Paulo, ano 05, n. 054.02, Vitruvius, jun. 2006 <http://www.vitruvius.com.br/revistas/read/resenhasonline/05.054/3138>. Acesso em: 11 out. 17.

[200-].

. Restauração e referenciais teóricos. Fórum Patrimônio, Uberlândia, v. 0, n. 0 ,

<http://www.forumpatrimonio.com.br/view_full.php?articlelD=164\&modo=1>. Acesso em: 12 out. 17.

KÜHL, B. M. Cesare Brandi e a teoria da restauração. Pós. Revista do Programa de PósGraduação em Arquitetura e Urbanismo da FAUUSP, n. 21, p. 197-211, 2007.

- História e ética na conservação e na restauração de monumentos históricos. Revista CPC, n. 1, p. 16-40, 2006.

. Notas sobre a Carta de Veneza. Anais do Museu Paulista: História e Cultura Material, v. 18, n. 2, p. 287-320, 2010.

OLIVEIRA, R. P. D. O idealismo de Viollet-le-Duc. Resenhas Online, São Paulo, ano 08, n. 087.04, Vitruvius, mar. 2009.2 Disponível em: <http://vitruvius.com.br/revistas/read/resenhasonline/08.087/3045>. Acesso em: 13 out. 17.

PACHALSKI, G. A. Museu do Pão: Arquitetura, Cultura e Lugar. Dissertação Mestrado em Arquitetura e Urbanismo. Programa de Pós-Graduação em Arquitetura e Urbanismo. UFPel, Pelotas, 2012.

SAMBIASI, S. Museu do Pão / Brasil Arquitetura. ArchDaily Brasil, 2011. Disponível em: <https://www.archdaily.com.br/8579/museu-do-pao-moinho-colognese-brasil-arquitetura>. Acesso em: 18 out. 2017. 